\title{
Geometrical dependence on the stress and slip tendency acting on the subduction megathrust of the Nankai seismogenic zone off Kumano
}

\author{
Masataka Kinoshita ${ }^{1 *} \mathbb{D}$, Kazuya Shiraishi ${ }^{2}$ Evi Demetriou ${ }^{3}$, Yoshitaka Hashimoto ${ }^{4}$ and Weiren Lin $^{5}$
}

\begin{abstract}
We assess the dependence of megathrust geometry near the updip edge of the Nankai seismogenic zone according to the slip tendency of the megathrust based on a reprocessed 3D PSDM seismic volume image and International Ocean Discovery Program (IODP) NanTroSEIZE drilling data off the coast of the Kii Peninsula, central Japan. The plate boundary fault surface is manually picked from the 3D seismic volume and is divided into three groups: low $\operatorname{dip}\left(10^{\circ}-15^{\circ}\right)$ trending NW to $\mathrm{N}$ in the NE region, intermediate dip $\left(\sim 25^{\circ}\right)$ trending north in the western region, and high dip $\left(30^{\circ}-40^{\circ}\right)$ trending NW in the SE corner. We then calculate the overburden $\left(S_{v}\right)$ by converting the modeled 3D velocity to bulk density. Here, $S_{v}$ ranges from $100 \mathrm{MPa}$ near the SW edge to $160 \mathrm{MPa}$ on the NE corner. In order to derive horizontal principal stresses $\left(S_{H}\right.$ and $\left.S_{h}\right)$ and the pore fluid pressure $\left(P_{p}\right)$, we assign the ratio of horizontal-to-vertical principal stresses, $r\left(=S_{H} / S_{V}\right)$, and the ratio of pore fluid pressure-to-vertical stress, $\lambda$ $\left(=P_{p} / S_{V}\right)$ based on IODP drilling data. The directions of $S_{H}$ and the slip on the fault are set parallel to the plate convergence vector (N55W). Assuming a triaxial condition $\left(S_{H}>S_{h}=S_{v}\right)$, the slip tendency $(T S)$ can be calculated from the dip angle and dip azimuth of the fault surface, $r$, and $\lambda$. We found that $T_{s}$ is sensitive to the variation in fault geometry. For $r=1.2$ and $\lambda=0.7$ (normalized pore pressure ratio $\left.\lambda^{*}=0.25\right)$, $T s$ is low $(\sim 0.1)$ in the low-angle dip region and higher $(>0.2)$ in the high-angle dip region. This suggests that the high-angle fault is optimally oriented under this condition. Low Ts in the low-angle dip region would correspond to a weaker region due to a low frictional strength, assuming that the fault surface should slip simultaneously. Using the high pore pressure ratio $\left(\lambda^{*} \sim 0.85\right)$ beneath the fault zone, the fault beneath IODP Site C0002 is very close to failure if $r>1.2$.
\end{abstract}

Keywords: Nankai Trough seismogenic zone, Slip tendency, IODP, 3D seismic volume, Stress tensor, Pore pressure

\section{Introduction}

According to the Coulomb failure theory, an earthquake or a slip along a fault can occur if the ratio of shear stress to effective normal stress exceeds the friction coefficient on the fault surface. This ratio is called the slip tendency $(T s)$. In order to estimate $T s$ along a pre-existing fault, we need to know the fault geometry (dip angle and dip azimuth), because the shear and normal stresses vary with dip.

\footnotetext{
* Correspondence: masa@eri.u-tokyo.ac.jp

'Earthquake Research Institute, The University of Tokyo, 1-1-1 Yayoi,

Bunkyo-ku, Tokyo 113-0032, Japan

Full list of author information is available at the end of the article
}

Subduction zone earthquakes occur along a plate boundary megathrust and have geometry that varies either within a main fault trace or by fault branching. Such fluctuation can lead to variation in $T s$ within a megathrust system.

In the present paper, we consider the case for the Nankai Trough seismogenic zone off Kumano, central Japan, which is one of the most well-studied subduction zones. From the reprocessed 3D PSDM volume, we obtained the fine-scale geometry (dip angle and azimuth) of the updip region of plate boundary fault. Integrating this fault geometry with deep drilling data obtained within the 3D survey region, we calculate the slip tendency of the fault and assess the degree to which the fault 
geometry affects the slip tendency value. Then, we discuss the implication of geometrical variation, e.g., whether shallow regions of the megathrust exhibit different behaviors at different times or locations, or whether pore fluid pressures and friction coefficients vary in different regions of the fault surface.

\section{Tectonic setting and previous research}

The Nankai Trough is a plate convergent boundary where the Philippine Sea Plate subducts beneath western Honshu, Japan. Geodetic observations (Miyazaki and Heki 2001) show that the plate convergence occurs at a rate of 63-68 mm/year in the N55W direction. DeMets et al. (2010) reported a similar value of $58.4 \pm 1.2 \mathrm{~mm} /$ year toward WNW.

In 1944, a 100-km-wide locked region of a subducting plate interface sheared, causing the devastating M8 Tonankai earthquake. The slip area of this event was estimated in several studies based on seismic inversion (Kikuchi et al. 2003; Ichinose et al. 2003) and tsunami inversion (Baba et al. 2006). The area with this coseismic slip (contours in Fig. 1) coincides with the present strong interseismic coupling, detected as a large slip deficit area inferred from seafloor geodetic measurements (Yokota et al. 2016). This indicates that the coupling/ locking condition is related to seismogenic conditions (i.e., rupture nucleation, propagation, and arrest).

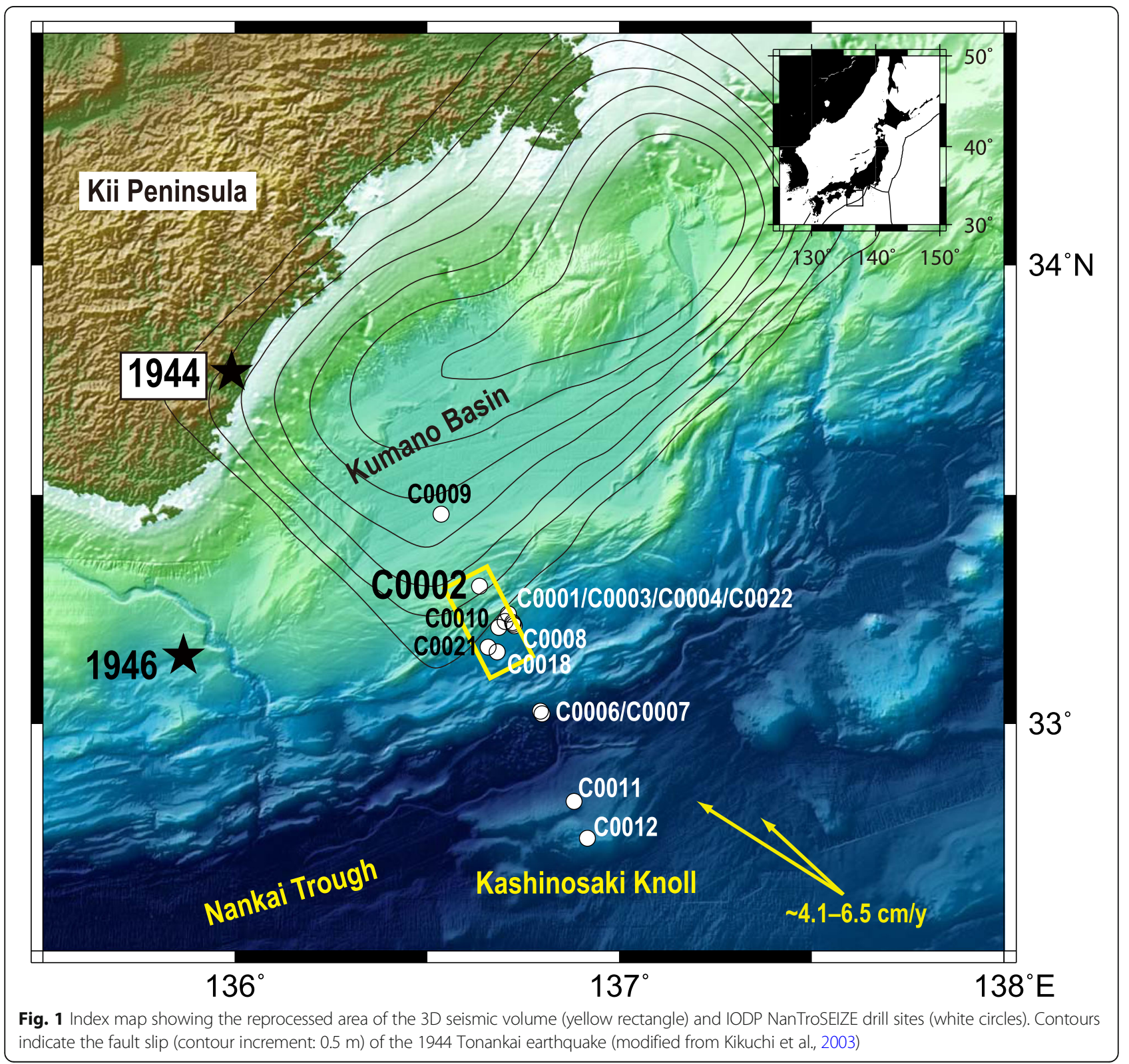


Intensive seismic monitoring using broadband seismometers or pressure gauges in the forearc region of the Nankai Trough off Kumano documented a wide spectrum of seismic activities, such as very-low-frequency events (VLFEs), low-frequency tremor (LFT) swarms, or slow slip events. Using the onshore broadband network (Hi-net), Obara and Ito (2005) detected the occurrence of VLFEs in the Nankai forearc region (including those off Kumano in 2004) with their focus located along the décollement or splay faults and thrust-type mechanisms. Obana and Kodaira (2009) observed low-frequency tremors near the shallowest region of a splay fault in the outer wedge of the accretionary prism off Kumano. Using four broad-band ocean bottom seismometers, Sugioka et al. (2012) detected VLFEs at the shallowest region of the plate boundary of the Nankai Trough in 2009, generated by slips along very low-angle thrusts. On April 1, 2016, the Mw 6.0 Mie-ken Nanto-Oki event occurred in the middle of the locked zone (e.g., Nakano et al. 2018). Although the focal depths differ among researchers, the main shock is supposed to have occurred on the plate interface with its mechanism being low-angle thrust-type dipping at either $14^{\circ}$ or $76^{\circ}$ (Wallace et al. 2016).

In order to understand the state and properties of the Nankai Trough seismogenic zone, a series of ocean scientific drillings has been conducted since 2007 as part of the Integrated Ocean Drilling Program (IODP) Nankai Trough Seismogenic Zone Experiments (NanTroSEIZE) (Fig. 1; Tobin and Kinoshita 2006; Kinoshita et al. 2009; Expedition 326 Scientists 2011; Henry et al. 2012; Kopf et al. 2011; Saffer et al. 2010; Saito et al. 2010; Screaton et al. 2009; Strasser et al. 2014; Tobin et al. 2009; Tobin et al. 2014; Kinoshita et al. 2014; Kopf et al. 2016). The ultimate goal of NanTroSEIZE is to core, log, and monitor the locked region of the plate boundary megathrust approximately $5 \mathrm{~km}$ below the seafloor at Site C0002.

One of the important components of NanTroSEIZE is to install borehole observatories for long-term monitoring of in situ pressure, temperature, strain, deformation, and seismicity. In 2010, the first permanent observatory was installed at approximately $900 \mathrm{mbsf}$ at Site C0002 above the updip limit of the locked zone during IODP Expedition 332 (Kopf et al. 2011). In 2016, the second observatory was installed at the shallow region of the megasplay fault zone at Site C0010 ( $400 \mathrm{mbsf})$ during IODP Expedition 365 (Kopf et al. 2011). Using data from both observatories, Araki et al. (2017) reported recurring slow-slip events (SSEs) on the plate interface immediately seaward of 1944 M8 earthquake rupture area, with their duration ranging days to weeks. They also reported swarms of low-frequency tremors following these SSEs.

A wide spectrum of seismicity suggests that the plate interface around the updip edge of the locked zone is sensitive to external stress because of the weakness of faults (Obara and Kato 2016). This is likely supported by the low-velocity zone extending along the décollement (Kamei et al. 2012; Park et al. 2010; Bangs et al. 2009).

Drilled core samples and in situ data (logging and downhole experiments) provide direct lines of information of the megathrust fault, but this has limited value unless this point-source information is properly extrapolated around the locked zone. Precise structural imaging at the plate boundary fault system and in accreted sediments is essential.

In 2006, 3D seismic reflection data acquisition and processing were carried out (Moore et al. 2007). However, the obtained volume could not necessarily resolve deep structures due to relatively short $(4.5 \mathrm{~km})$ streamers and the strong Kuroshio current. In 2016, this seismic volume was reprocessed using state-of-the-art advanced technology (e.g., better attenuation of noise and multiple reflections, broadband processing with deghosting, and 4D regularization to mitigate non-uniform fold distribution caused by the Kuroshio current) in order to obtain clearer images and a more reliable $\mathrm{P}$-wave velocity $\left(V_{p}\right)$ model (Shiraishi et al. 2016). Improved images in the shallow accretionary wedge revealed deformation features (e.g., branching of splay faults and thrusting of the lower Shikoku Basin formation). However, due to short streamer length, the spatial resolution in deeper regions was not improved significantly after reprocessing in 2016. This gives rise to an inherent uncertainty in the geometry of the plate boundary fault. Despite such limitations, we used the reprocessed 3D data, which are the best data available thus far around the drill site.

\section{Methods/Experimental}

Figure 2 shows an outline of the method used in the present study and is explained in the following.

\section{Slip tendency and slip likelihood}

Slip tendency was first proposed by Morris et al. (1996) for the assessment of potential fault activity among multiple pre-existing faults under a uniform stress state:

$$
T s=\tau /\left(\sigma_{n}-P_{p}\right),
$$

where $\tau$ is the shear stress, $\sigma_{n}$ is the normal stress acting on a plane, and $P_{p}$ is the pore fluid pressure (see Table 1 for definitions of parameters).

Tong and Yin (2011) revised this model to include the cohesive shear strength and defined a new index, the reactivation tendency, as $\tau /\left(\tau_{O}+\mu \sigma_{n \_}\right)$, where $\tau_{O}$ is the cohesion strength, $\mu$ is the intrinsic frictional coefficient, and $\sigma_{n e}$ is the effective normal stress.

Although this definition describes the "likelihood" of fault slip, in the present study, we use the definition of 


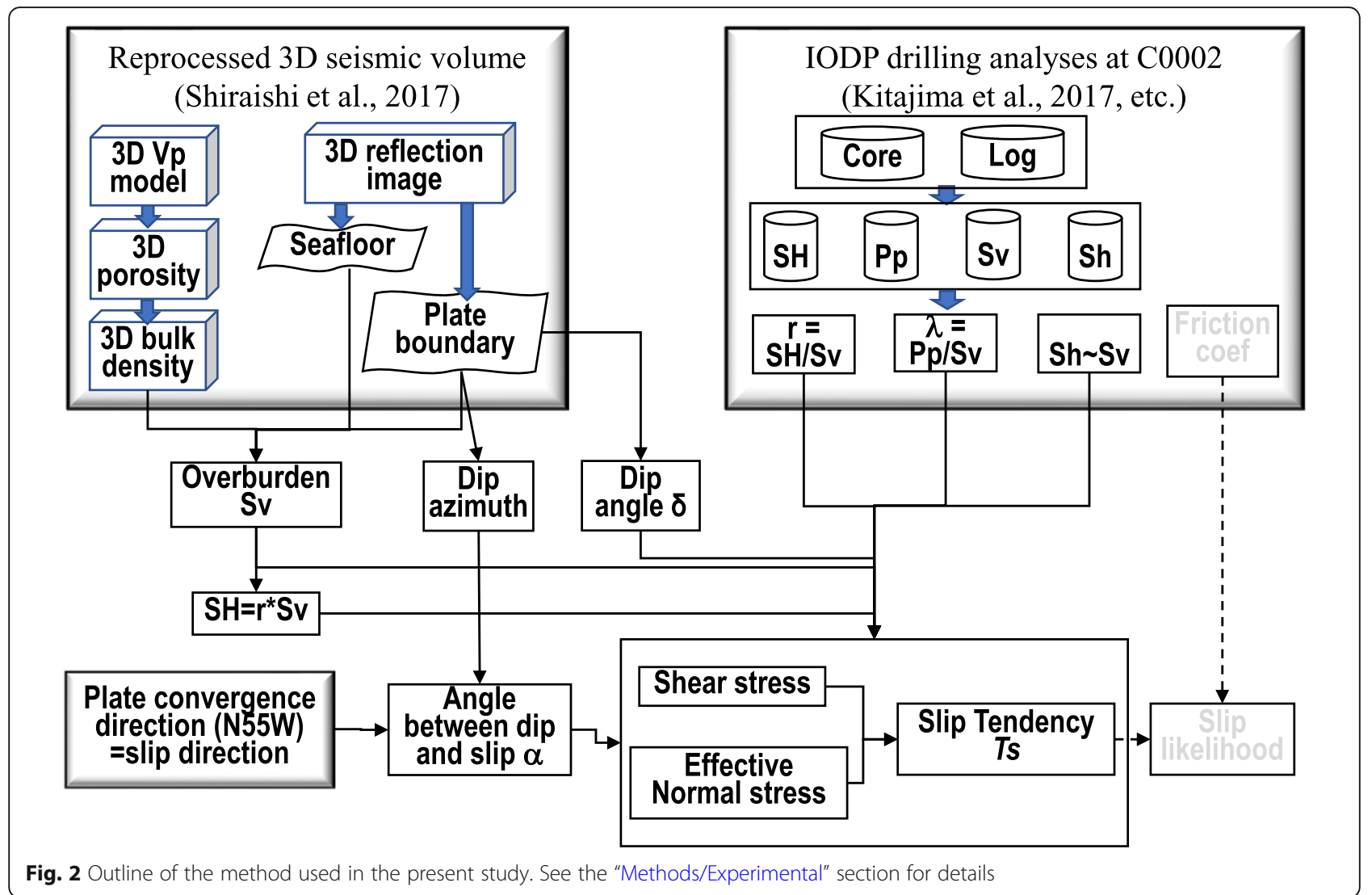

Morris et al. (1996) in Eq. (1) because, as of yet, we have no measurements on the intrinsic frictional coefficient on the fault, and because the cohesive strength is negligibly small in a reverse faulting regime in subduction zone megathrusts. A similar approach was taken by Miyakawa and Otsubo (2015) for the assessment of fault activity in NE Japan.

Alternatively, we use the slip likelihood (SL), which is defined as

$$
\mathrm{SL} \equiv \frac{1}{\mu} \cdot \frac{\tau}{\sigma_{n}-P_{p}}=\frac{1}{\mu} \cdot T_{s} .
$$

According the Coulomb failure criterion, the fault will slip if $\mathrm{SL}=1$.

Templeton and Rice (2008) proposed an alternative definition of slip likelihood, closeness to failure (CF), which is defined as the distance between the Mohr circle and failure criteria. Since SL and CF are essentially identical, we herein use $T s$ and SL, mainly for reasons of simplicity.

\section{Picking a fault reflector from the 3D seismic volume}

The plate boundary fault was extracted from the reprocessed 3D seismic volume using Petrel $^{\circ}$ software in the area shown in Figs. 1 and 3 shows an example of a fault surface, which is manually picked by eye along the negative-polarity peaks (shown as blue) beneath the positive and generally strongest peaks. Reflection images for the reprocessed volume are clearer than the original images but still suffer from insufficient spatial resolution and migration noise because of the great depth of the volume. As shown in Fig. 3, the wavelength of reflected waves from the plate boundary fault is approximately $200 \mathrm{~m}$. Since the seismic resolution is usually considered to be approximately $1 / 4$ the dominant wavelength, the spatial resolution is approximately $50 \mathrm{~m}$. We found some discontinuities in the reflectors, in which case, we attempted to follow as smooth a trend as possible. The picked surface is then smoothed in Petrel, but artificial fluctuations remain due to picking error or systematic offset among inlines. Overall, we assess that the relative uncertainty in the depth of the fault can be as large as $\pm 50 \mathrm{~m}$.

\section{Vertical stress on the fault}

The vertical stress applied to the fault surface is estimated from the 3D P-wave velocity model following the procedure in Fig. 2.

Erickson and Jarrard (1998) developed a global empirical relationship between P-wave velocity and porosity for consolidated and non-consolidated siliciclastic sediments, 
Table 1 List of parameters

\begin{tabular}{|c|c|c|}
\hline Notation & Definition & $\begin{array}{l}\text { Assignment/derivation } \\
\text { for this study }\end{array}$ \\
\hline $\begin{array}{l}\text { Sign } \\
\text { of stress }\end{array}$ & & $\begin{array}{l}\text { Positive for } \\
\text { compression }\end{array}$ \\
\hline$\psi$ & Dip azimuth (clockwise from north) & \\
\hline$a$ & $\begin{array}{l}\text { Angle between } S_{H} \text { (slip) direction } \\
\text { and dip azimuth }\end{array}$ & $a=\psi-\left(-55^{\circ}\right)$ \\
\hline$\delta$ & Dip angle (positive downward) & \\
\hline$\sigma_{1}$ & $\begin{array}{l}\text { Maximum compressional principal } \\
\text { stress }\end{array}$ & $\sigma_{1}=S_{H}$ \\
\hline$\sigma_{2}$ & Intermediate principal stress & $\sigma_{2}=S_{h}$ \\
\hline$\sigma_{3}$ & Minimum principal stress & $\sigma_{3}=S_{V}$ \\
\hline$S_{H}$ & $\begin{array}{l}\text { Maximum (compressional) horizontal } \\
\text { principal stress }\end{array}$ & $S_{H}=r S_{V}=1.2 S_{V}$ \\
\hline$S_{h}$ & Minimum horizontal principal stress & $S_{h}=S_{V}$ \\
\hline$S_{V}$ & Vertical stress (overburden) & $\begin{array}{l}\text { Calculated from } \\
\text { 3D density }\end{array}$ \\
\hline$P_{p}$ & Pore fluid pressure & $P_{p}=\lambda S_{V}=0.7 S_{V}$ \\
\hline$P_{\text {hyd }}$ & Hydrostatic pore fluid pressure & $P_{\text {hyd }}=0.6 S_{V}$ \\
\hline$\sigma_{H}$ & Effective maximum horizontal stress & $\sigma_{H}=S_{H}-P_{p}$ \\
\hline$\sigma_{h}$ & Effective minimum horizontal stress & $\sigma_{h}=S_{h}-P_{p}$ \\
\hline$\sigma_{v}$ & Effective vertical stress & $\sigma_{v}=S_{v}-P_{p}$ \\
\hline$\Sigma$ & Stress tensor & \\
\hline r & $S_{H} / S_{V}$ & $r=1.2$ \\
\hline$\lambda$ & $P_{p} / S_{V}$ & $\lambda=0.7,0.94$ \\
\hline$\lambda^{*}$ & $\left(P_{p}-P_{\text {hyd }}\right) /\left(S_{v}-P_{\text {hyd }}\right)$ & $\lambda^{*}=0.2,0.85$ \\
\hline$\sigma_{n}$ & Normal stress & \\
\hline$\sigma_{n \_e}$ & Effective normal stress & $\begin{array}{l}\sigma_{n-e}=\sigma_{n}-P_{p} \\
\text { (Eq. (7)) }\end{array}$ \\
\hline$\tau$ & Shear stress & Eq. (8) \\
\hline Ts & Slip tendency & $\begin{array}{l}T s=T / \sigma_{n \_}, \\
(\text {Eq. }(9))\end{array}$ \\
\hline$\mu$ & Intrinsic friction coefficient & $\mu=0.6$ \\
\hline$S L$ & Slip likelihood & $S L=T s / \mu$ \\
\hline$V_{p}$ & P-wave velocity & \\
\hline
\end{tabular}

covering a velocity range of up to approximately $5 \mathrm{~km} / \mathrm{s}$ and a full range of porosity (0-1). Kitajima et al. (2017) used this relation to determine the in situ porosity from Vp logs at IODP Site C0002. Above the picked fault surface, the $\mathrm{Vp}$ from the reprocessed 3D model ranges from 1.5 to $5.5 \mathrm{~km} / \mathrm{s}$ (Shiraishi et al. 2016), and the estimated bulk density ranges from 1.5 to $2.7 \mathrm{~g} / \mathrm{cm}^{3}$. In order to convert porosity to bulk density, the grain density is estimated for core samples at Site C0002. The grain density increases slightly from $2.68 \mathrm{~g} / \mathrm{cm}^{3}$ at $950.5 \mathrm{mbsf}$ to $2.72 \mathrm{~g} /$ $\mathrm{cm}^{3}$ at $3058.5 \mathrm{mbsf}$ (Tobin et al. 2015). The vertical stress $\left(S_{v}\right)$ is calculated by integrating the bulk density from the sea surface to the fault surface.
The effective vertical stress is calculated by subtracting the pore fluid pressure $\left(P_{p}\right)$ from $S_{v}$. Tsuji et al. (2014) estimated the pore fluid pressure from the velocity anomaly obtained through full-wave inversion of the wide-angle seismic refraction data in this region. According to their estimation, the normalized pore pressure ratio $\lambda *$, defined as

$$
\lambda^{*}=\frac{P_{p}-P_{h y d}}{S_{v}-P_{h y d}} P_{h y d}: \text { hydrostatic pressure. }
$$

is 0 to 0.5 in the hanging wall accretionary prism, with a higher value $(\sim 0.7)$ around Site C0002. On the other hand, Kitajima et al. (2017) estimated $\lambda *$ to be less than 0.2 (Fig. 4). In the present study, we follow the estimates of Kitajima et al., where $\lambda^{*}=0.25$, or $\lambda=P p / S v \sim 0.7$. This likely simulates the state on the hanging wall side of the fault. Since the fault zone itself and the footwall side can have a higher $\lambda$ * value $(\sim 0.85$, as predicted by Tsuji et al. 2014), we consider these two cases for Ts estimation.

The effective vertical stress $\sigma_{v}$ is shown as

$$
\begin{aligned}
\sigma_{v} & =S_{v}-P_{p}=(1-\lambda) S_{v}=\left(1-\lambda^{*}\right)\left(1-\lambda_{h}\right) S_{v} \\
& =0.4\left(1-\lambda^{*}\right) S_{v},
\end{aligned}
$$

where $\lambda_{h}=P_{h y d} / S_{v} \sim 0.6$ (Fig. 4).

For convenience, the relation between $\lambda$ and $\lambda *$ in the present study is

$$
\lambda^{*}=\left(\lambda-\lambda_{h}\right) /\left(1-\lambda_{h}\right) \sim(\lambda-0.6) / 0.4 .
$$

\section{Horizontal principal stresses}

Since we have the 3D geometry of the plate boundary fault, the stress acting on the fault must also be considered to be 3D. Assuming the vertical stress $\left(S_{v}\right)$, the maximum and minimum horizontal stresses $\left(S_{H}\right.$ and $S_{h}$ ) are the principal stresses. In the following, $S_{H}$ and $S_{h}$ are given for a thrust-faulting regime.

\section{Magnitude of $S_{H}$}

The magnitude of horizontal stresses in the crust is a long-standing issue in geomechanics. For a non-tectonic sedimentary basin, the state of stress is lithostatic (McGarr 1988), where all three principal stresses are identical (e.g., $S_{H}=S_{h}=S_{v}$ ). Zoback (2007) indicated that the crust is in a state of incipient frictional failure. In such a case, we can predict the principal stress field if the faulting regime (normal, strike-slip, or thrust) and an appropriate value of the frictional coefficient are given.

Brown and Hoek (1978) reviewed and compiled the results of in situ stress measurements and concluded that the ratio of average horizontal-to-vertical stressed varies in a wide range $(0.5$ to $>3.5)$, although this ratio generally decreases with increasing depth. Rummel et al. 



Fig. 3 Example of picked reflection from the fault surface. (Left) Shallow section (seafloor to the bottom simulating reflector). (Right) Deep section (plate boundary fault and top of oceanic crust). By comparing with those from seafloor (positive), BSR (negative), and top of oceanic crust (positive), the picked fault has a negative polarity

(1986) summarized that the ratio of maximum compressional stress to the minimum compression stress was slightly above 1 below a depth of $1 \mathrm{~km}$ in the continental crust.

Based on geomechanical experiments on core samples drilled in this area, Kitajima et al. (2017) estimated the horizontal maximum principal stress $\left(S_{H}\right)$ and pore fluid pressure $\left(P_{p}\right)$ along Site C0002 down to 3000 mbsf. Figure 4 indicates that the ratio of maximum-to-minimum compression stresses, or $S_{H} / S_{v}(=r)$ in this case, is 1.0 to 1.4 at Site C0002. Here, we assume $r=1.2$ on the plate boundary fault. For effective stress $\sigma_{H}$, we make a similar assumption regarding $S_{v}$ :

$$
\sigma_{H}=S_{H}-P_{p}=(r-\lambda) S_{v}=\left(r-0.4 \lambda^{*}-0.6\right) S_{v} .
$$

\section{Azimuth of $S_{H}$ and slip}

We simply assume that $S_{H}$ is oriented parallel to the plate convergence vector. The plate convergence vector between the AM and PH plates is estimated as N55W at a rate of 63 to $68 \mathrm{~mm} /$ year (Miyazaki and Heki 2001) based on geodetic data. DeMets et al. (2010) reported a rate of $58.4 \pm 1.2 \mathrm{~mm} /$ year in the WNW direction. In the present study, we adopt N55W as the azimuth of $S_{H}$.
We also need to determine the slip direction in order to estimate the shear stress. A simple but reasonable assumption is that the slip direction is parallel to the maximum horizontal stress $\left(S_{H}\right)$, which is parallel to the plate convergence (N55W; Fig. 5).

\section{Horizontal minimum stress $S_{h}$}

Ito et al. (2009) estimated the stress ratio from the stress tensor inversion analysis of VLFEs and concluded that the intermediate stress ( $S_{h}$ for this case) is larger than the minimum principal stress $\left(S_{v}\right)$ in the off-Kumano region.

On the other hand, the minimum horizontal stress $\left(S_{h}\right)$ was estimated through downhole measurements (Leak-off test; Strasser et al. 2014; Tobin et al. 2015), which indicates that $S_{h}$ is slightly (several $\mathrm{MPa}$ ) smaller than $S_{v}$ at depths of 2000 mbsf, suggesting a normal faulting or strike-slip regime.

Although the stress regime is different across the plate boundary fault, horizontal stresses should be larger than the vertical stress for a reverse fault. Since there are no constraints on the principal stresses near the plate interface at present, we assume a triaxial state, in which the minimum horizontal stress $\left(S_{h}\right)$ is equal to $S_{v}$, which yields

$$
\sigma_{H}>\sigma_{h}=\sigma_{v},
$$



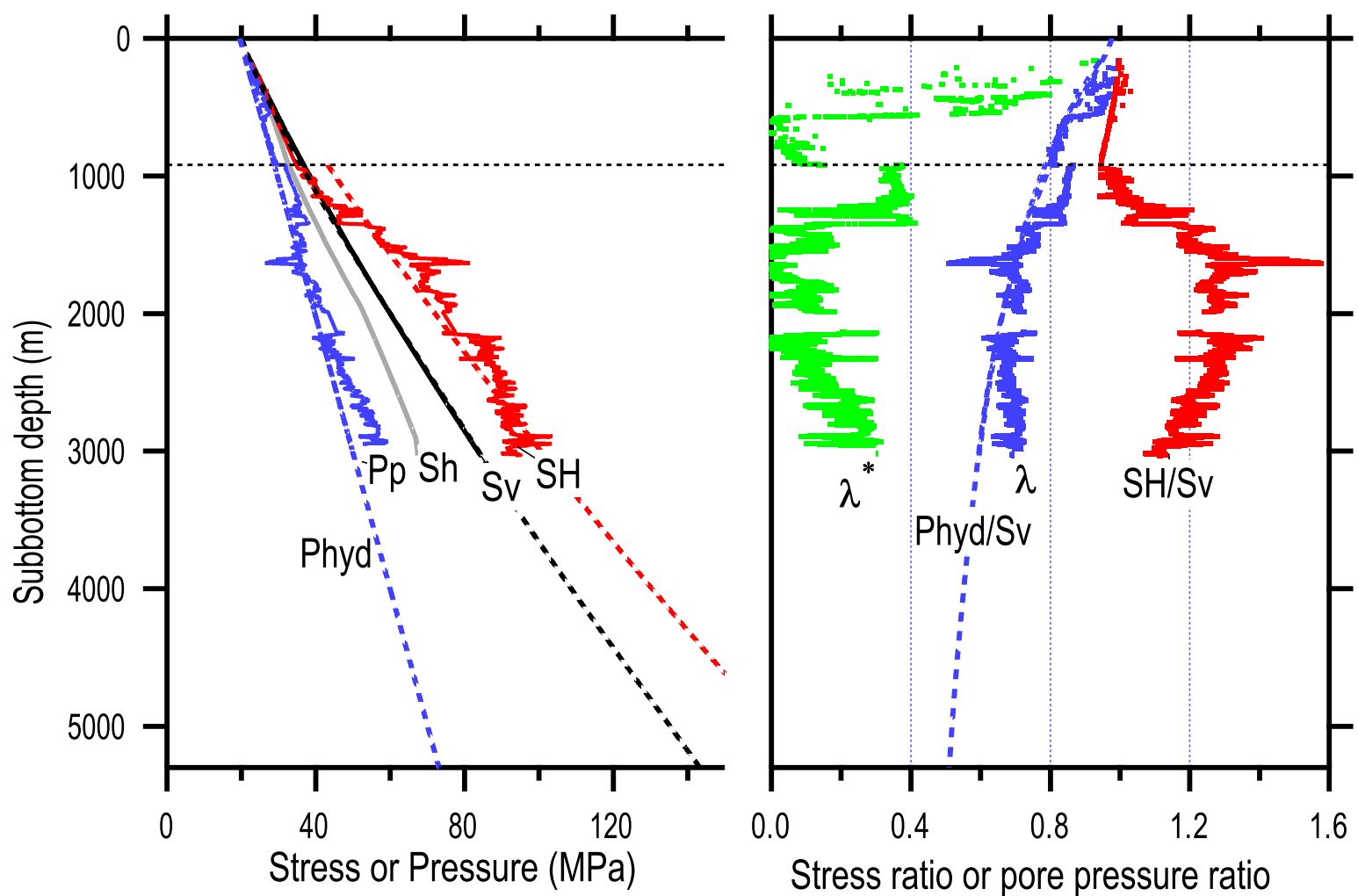

Fig. 4 (Left) Principal stress and pore fluid pressure estimated by Kitajima et al. (2017). (Right) Estimated pore pressure ratio, normalized pore pressure ratio, and stress ratio. $S_{H}$ : maximum (compressional) horizontal stress, $S_{h}$ : minimum horizontal stress, $S_{v}$ : vertical stress, $P_{p}$ : pore fluid pressure, and $P_{\text {hyd }}$ : hydrostatic pore pressure. $\lambda=P_{p} / S_{v} \lambda^{*}=\left(P_{p}-P_{\text {hyd }}\right) /\left(S_{v}-P_{\text {hyd }}\right)$. The dotted curves are the stress and pore fluid pressure models used to calculate the slip tendency, Ts

where $\sigma_{H}$ and $\sigma_{h}$ are the effective maximum and minimum horizontal stresses, respectively.

\section{Normal/shear stress and slip tendency}

We now have all the necessary information to calculate the effective normal stress and shear stress: the effective principal stresses (magnitude, direction, and pore fluid pressure), geometry (dip angle and dip azimuth) of the plate boundary fault, and the potential slip direction (N55W). The effective normal stress and shear stress acting at each location on the plate boundary fault are

$$
\begin{aligned}
\sigma_{n_{-} e}= & {\left[\left((\sin \alpha \sin \delta)^{2}+(\cos \delta)^{2}\right)(1-\lambda)+(\cos \alpha \sin \delta)^{2}\right.} \\
& (r-\lambda)] S_{v} .
\end{aligned}
$$

$$
\tau=A \sin \delta \cos \delta(r-1) S_{v}
$$

where $A=\left(\frac{\cos ^{2} \delta}{\cos ^{2} \alpha}+\sin ^{2} \delta\right)^{-1 / 2}$

(see Table 1 for notation, and Appendix for derivation of these equations).
From Eq. (1), the slip tendency is calculated as

$$
T_{s}=\frac{\sin \delta \cos \delta(r-1)}{\sqrt{\left(\frac{\cos \delta}{\cos \alpha}\right)^{2}+\sin ^{2} \delta}\left[\left(\cos ^{2} \delta+\sin ^{2} \alpha \sin ^{2} \delta\right)(1-\lambda)+(\cos \alpha \sin \delta)^{2}(r-\lambda)\right]} .
$$

\section{Results}

\section{Geometry of the plate boundary fault}

Figure 6 shows the geometry of the picked plate boundary fault. The fault is shallowest ( $3500 \mathrm{mbsf})$ near the SW edge and deepest (6500 mbsf) near the NE edge. On the NE to NW side, the dip angle is $10^{\circ}$ to $15^{\circ}$, and the azimuth runs approximately NW, whereas on the NW side, the dip angle is approximately $25^{\circ}$, and the azimuth runs approximately N. On the NW side, the fault is generally shallower, which may be related to the shallow seafloor. Moreover, note that the strike of the outer ridge on the seafloor is ENE on the eastern side and changes to NE on the western side (Kimura et al. 2011).

On the seaward side, the fault geometry has a planer shape, where the dip angle is $30^{\circ}$ to $40^{\circ}$, which is significantly larger than on the landward side, and the dip 


azimuth is NNW. This higher-angle structure appears to branch out from the low-angle reflector (as indicated above).

\section{Principal stresses}

Figure 7 shows the vertical stress $\left(S_{v}\right)$ on the fault. Here, $S_{v}$ is lowest around $105 \mathrm{MPa}$ near the SW edge (3500 mbsf) and is higher than $160 \mathrm{MPa}$ in the NE corner. The variation in $S_{v}$ is mostly due to the variation of the fault depth. As mentioned in the "Introduction" section, $V_{p}$ in the deeper region should have large uncertainties. The density anomaly, corresponding to a possible high $V_{p}$ anomaly in the NE region above the fault $(\sim 1 \mathrm{~km} / \mathrm{s}$ higher than the surrounding area; Shiraishi et al., this volume), is $+0.2 \mathrm{~g} /$ $\mathrm{cm}^{3}$. The density anomaly could produce an additional overburden of approximately $2 \mathrm{MPa}$ (assuming that the $V_{p}$ anomaly is $1 \mathrm{~km}$ thick).

The horizontal maximum stress $\left(S_{H}\right)$ is calculated using Eq. (6) and ranges from 100 to $200 \mathrm{MPa}$, which is attributed to the variation in $S_{v}$ (note that $r$ is kept constant in our model). As stated in the "Methods/Experimental" section, $S_{h}=S_{v}$ (and thus $\left.\sigma h=\sigma v\right)$.

\section{Slip tendency}

Figure 8a through d indicates the effective normal stress, the shear stress, and the slip tendency of the fault. As described in the "Methods/Experimental" section, we used $r$ $=S_{H} / S_{v}=1.2$ and $\lambda^{*}=0.25(\lambda=0.7)$. For later discussion, the Ts value with $\lambda^{\prime \prime}=0.85(\lambda=0.94)$ is also plotted in Fig. 8 .

The effective normal stress ranges from 25 to $60 \mathrm{MPa}$. As recognized from Eq. (8), small values in the SW corner are due not only to the shallow depth (or small $S_{v}$ ) but also to the geometry (dip angle and azimuth). Note that we assume a near-hydrostatic pore fluid pressure based on Kitajima et al. (2017). For an overpressurized fault, the effective normal stress should decrease. The shear stress ranges from 0 to $20 \mathrm{MPa}$ and depends on $S_{v}$, but is more sensitive to the variation in the dip angle than to $S_{v}$.

For a case with $\lambda^{*}=0.25(\lambda=0.7)$ (Fig. 8), the slip tendency $T s$ varies from 0.05 to 0.1 on the $\mathrm{N}$ to NE side and from 0.15 to 0.2 in the center to the SW side. Moreover, $T s$ is larger than 0.2 on the SE side, mainly due to larger dip angle. For the case with $\lambda^{*}=0.85(\lambda=0.94), T s$ in the shallow dip region ( $\mathrm{N}$ to $\mathrm{NW}$ side) varies from 0.2 to 0.6 and is larger than 0.6 on the SE side.

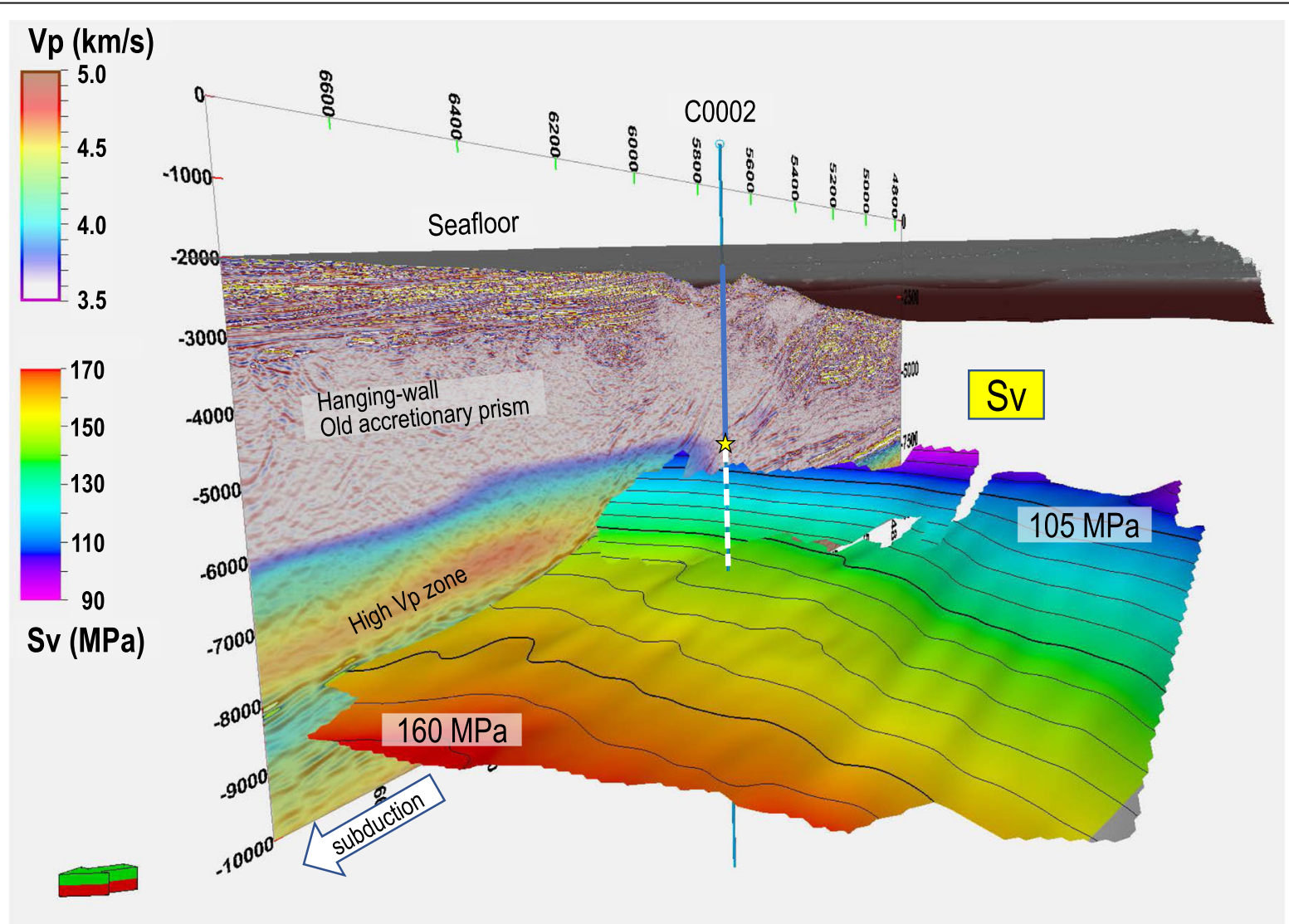

Fig. 7 Vertical stress, $S_{v}$, scaled between $90 \mathrm{MPa}$ (purple) and $170 \mathrm{MPa}$ (red). Contours indicate the depth of the fault (meters below the sea surface). Half-transparent colors on the inline PSDM image indicate the P-wave velocity scaled between $~ 3.5 \mathrm{~km} / \mathrm{s}$ (blue) and $5 \mathrm{~km} / \mathrm{s}$ (red). There is no vertical exaggeration. The yellow star at the drill site (Site C0002) indicates the current total drilled depth, and the white broken line indicates the planned drill path in 2018 


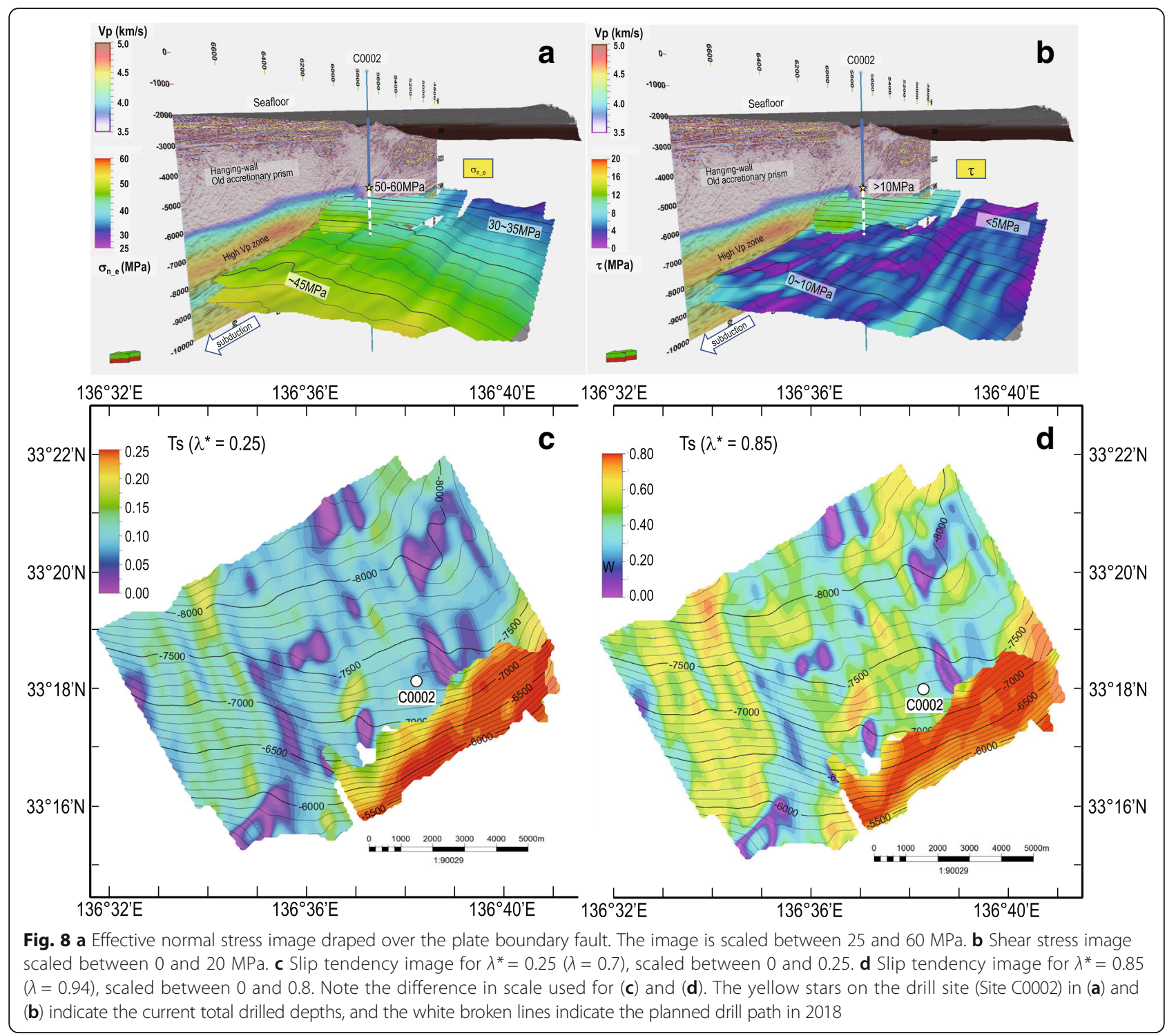

The slip tendency can also be shown on a lower-hemisphere equal-angle stereographic chart (Fig. 9), where the dip angle $\delta$ is shown along the radial axis, and the dip azimuth is shown along the azimuthal axis. Colored contours correspond to the amplitude of $T s$ with $r=1.2$ and $\lambda^{\prime \prime}=0.25(\lambda=0.7)$. Black dots indicate the dip angle and azimuth distribution for the picked fault.

The dots are distributed radially with most dip angles distributed at approximately $10^{\circ}$, where $T s$ is generally low $(\sim 0.1)$, and are distributed around NNW, where Ts is higher than 0.2. The triangle corresponds to the fault geometry below Site C0002, where dip angle is $6^{\circ}$, and thus $T s$ is smaller than 0.1. The color image in Fig. 9 shows the critical pore pressure ratio $\lambda^{*}{ }_{c r}$ at which the value of the slip likelihood (SL) becomes 1, assuming an intrinsic friction coefficient of 0.6 (e.g., Byerlee 1978). Here, $\lambda^{*}{ }_{c r}$ is larger than 0.85 , where the dip angle is approximately $10^{\circ}$ (suggesting that a higher pore fluid pressure is required for slip), whereas $\lambda^{*}{ }_{c r}$ is smaller, approximately 0.7 to 0.75 , in the higher-angle region (most likely on the SE side).

\section{Discussion}

\section{Uncertainty in Ts}

As shown in Eq. (10), the value of Ts depends on the fault dip angle and azimuth, $S_{H} / S_{\nu}(=r)$, as well as the pore pressure ratio $(\lambda$ or $\lambda *$ ). Here, we estimate the uncertainties of these parameters and eventually assess the uncertainty in $T s$.

The uncertainty due to picking the reflectors $( \pm 50 \mathrm{~m}$; see the "Methods/Experimental" section) leads to uncertainty in the dip angle, depending on the value of the dip angle. For a region with a shallow dip angle (approximately $10^{\circ}$ ), the uncertainty is $\pm 7^{\circ}$, resulting in $T s=0.1 \pm 0.05$. For 

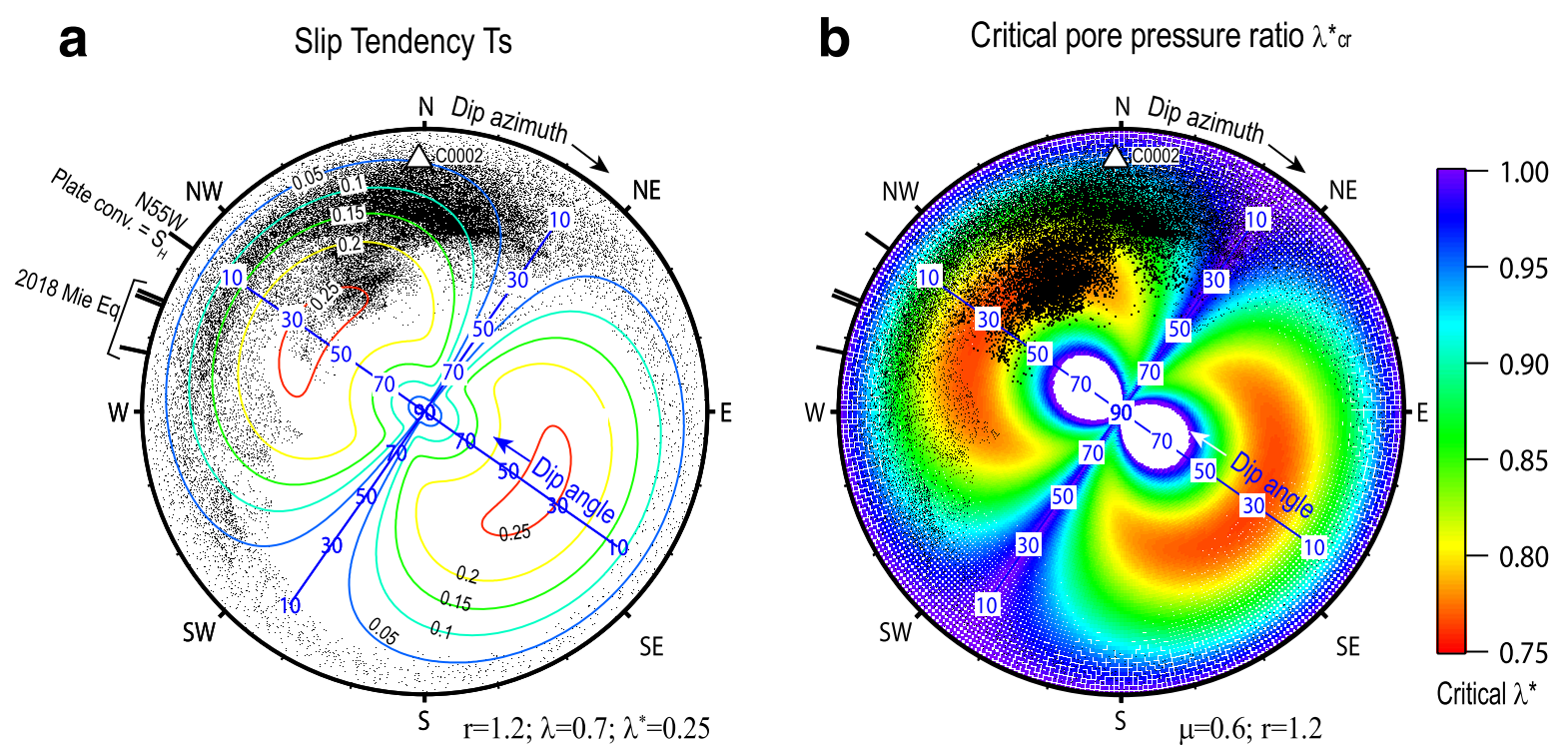

Fig. 9 a Slip tendency Ts shown as colored contours on a lower-hemisphere equal-angle stereographic chart, where the dip angle $\delta$ is taken along the radial axis, and the dip azimuth is taken along the azimuthal axis. Color corresponds to the amplitude of Ts, with $r=1.2$ and $\lambda^{*}=0.25$ ( $\left.\lambda=0.7\right)$. The black dots indicate the dip angle and azimuth distribution for the picked fault. The triangle corresponds to the fault geometry below Site C0002. The plate slip direction is equal to the $S_{H}$ direction (N55W). The slip direction of the 2016 Mie-ken Nanto-Oki event was obtained from the Japan Meteorological Agency (JMA) and U.S. Geological Survey (USGS). b The critical pore-pressure ratio $\lambda^{*}{ }_{c r}$ is the value at which the slip likelihood (SL) becomes 1 , assuming that the intrinsic friction coefficient is 0.6 and $P_{\text {hyd }} / S_{V}=0.6$

a steep dip region (approximately $30^{\circ}$ in the SE corner), the uncertainty is $\pm 5^{\circ}$, resulting in $T s=0.23 \pm 0.05$.

The uncertainty in the dip azimuth is difficult to assess, but based on its spatial distribution in Fig. 6, is probably approximately $20^{\circ}$. We recognize that $T s$ is not very sensitive to the variation in the dip azimuth (Fig. 9). We assess that the uncertainty in $T s$ due to that in the dip azimuth is less than 0.05 .

The possible additional overburden of approximately $2 \mathrm{MPa}$ due to high $V p$ above the fault would decrease $r$ to 1.18 if $S_{H}$ remained unchanged. This might reduce $T s$ by 0.01 to 0.03 (Fig. 10). As stated in the previous section (Horizontal principal stresses), the stress ratio $r$ should probably vary from 1.0 to 1.4 . Figure 10 shows that the variation in $T s$ due to variation in $r$ ranges from 0.01 to 0.16 for the nearly hydrostatic case $(\lambda *=0.25$ or $\lambda=0.7)$, whereas $T s$ varies from $0.04(r=1)$ to $0.79(r=$ 1.4) for the case of an overpressure $\left(\lambda^{*}=0.85\right.$ or $\left.\lambda=0.94\right)$.

\section{Fault geometry is not optimally oriented}

As described in the "Results" section, the peak population in the dip angle and the azimuth in Fig. 9 (dots in both panels) is significantly offset from the peak in $T s$ (color image). This indicates that most of the fault region is not optimally oriented. In other words, most regions of the fault plane must have some mechanism to "transform" their optimal dip (predicted from $T s$ ) into the actual dip. In the following, we first discuss the offset in the dip angle, followed by the offset in the dip azimuth.

\section{Fault dip angle is shallower than at the Ts peak}

The main population of the fault dip angle is approximately $10^{\circ}$ (except for $\sim 30^{\circ}$ in the SE corner), whereas the Ts peak [shown by the contours in Fig. 9a] corresponds to a dip angle of $30^{\circ}$ to $40^{\circ}$. This can be reconciled if the frictional strength is weaker along the pre-existing, lower-angle $\left(\sim 10^{\circ}\right)$ fault surface than the surrounding rock. Figure 11 shows the case in which the pre-existing fault (with dip angle $\delta_{2}$ ) is incipiently weaker than the host rock. For this case, if the pore fluid pressure increases (i.e., the Mohr circle moves leftward in Fig. 11) with time, then this pre-existing, low-angle thrust will be reactivated (leftmost circle).

In the present study, we assume that the principal stresses are oriented horizontally and vertically. This inference may be supported by the results of Ito et al. (2009), who estimates that $\sigma_{1}$ (maximum principal stress) is oriented horizontally for the VLFEs that occurred near the trench axis in the forearc slope region off Kumano. However, in deeper fault zones, the $\sigma_{1}$ axis can be tilted seaward. For the 2011 Tohoku earthquake case, Hasegawa et al. (2011) estimated the distributions of the P- and T-axes of the earthquake focal mechanisms before and after 2011 Tohoku earthquake. The distributions clearly indicate that most of the events have P-axes that dip seaward. If $\sigma_{1}$ is tilted seaward by approximately $20^{\circ}$ in the present study, 


\section{Pore pressure ratio}

$\begin{array}{lllllllllllllllllllllll}\lambda * & 0.2 & 0.25 & 0.3 & 0.35 & 0.4 & 0.45 & 0.5 & 0.55 & 0.6 & 0.65 & 0.7 & 0.75 & 0.8 & 0.8 & 0.83 & 0.85 & 0.9 & 0.9 & 0.93 & 0.95 & 0.98 & 1\end{array}$

$\begin{array}{lllllllllllllllllllllll}\lambda & 0.68 & 0.7 & 0.72 & 0.74 & 0.76 & 0.78 & \mathbf{0 . 8} & 0.82 & 0.84 & 0.86 & 0.88 & \mathbf{0 . 9} & 0.91 & 0.92 & 0.93 & 0.94 & 0.95 & 0.96 & 0.97 & 0.98 & 0.99 & 1\end{array}$ \begin{tabular}{llllllllllllllll|l|llllll}
1.02 & 0.01 & 0.01 & 0.01 & 0.01 & 0.01 & 0.01 & 0.01 & 0.01 & 0.02 & 0.02 & 0.02 & 0.03 & 0.03 & 0.03 & 0.04 & 0.04 & 0.05 & 0.07 & 0.09 & 0.13 & 0.25 & 7.45
\end{tabular} $\begin{array}{llllllllllllllllllllllllllllll}1.04 & 0.02 & 0.02 & \text { Slip Tendency } & 03 & 0.03 & 0.03 & 0.04 & 0.04 & 0.05 & 0.06 & 0.07 & 0.07 & 0.09 & 0.10 & 0.13 & 0.17 & 0.25 & 0.49 & 7.45\end{array}$ $\begin{array}{lllllllllllllllllllllllll}1.06 & 0.02 & 0.03 & \text { azimuth=N15W } & 0.04 & 0.05 & 0.06 & 0.07 & 0.08 & 0.09 & 0.10 & 0.11 & 0.13 & 0.15 & 0.19 & 0.25 & 0.38 & 0.72 & 7.45\end{array}$


$1.10 .040 .04 \mathrm{dip}=10^{\circ}, \mu=0.6 \quad \begin{array}{llllllllllllllllllll}.07 & 0.07 & 0.08 & 0.09 & 0.11 & 0.13 & 0.14 & 0.16 & 0.18 & 0.21 & 0.25 & 0.32 & 0.41 & 0.61 & 1.12 & 7.45\end{array}$ $\begin{array}{llllllllllllllllllllllllll}1.12 & 0.05 & 0.05 & 0.06 & 0.06 & 0.07 & 0.07 & 0.08 & 0.09 & 0.10 & 0.11 & 0.13 & 0.15 & 0.17 & 0.19 & 0.22 & 0.25 & 0.30 & 0.38 & 0.49 & 0.72 & 1.30 & 7.45\end{array}$ $\begin{array}{llllllllllllllllllllllllllll}\boldsymbol{\boldsymbol { D }} & 1.14 & 0.06 & 0.06 & 0.07 & 0.07 & 0.08 & 0.08 & 0.09 & 0.10 & 0.11 & 0.13 & 0.15 & 0.18 & 0.20 & 0.22 & 0.25 & 0.30 & 0.35 & 0.43 & 0.57 & 0.82 & 1.48 & 7.45\end{array}$ $\begin{array}{llllllllllllllllllllllllllll}\mathbf{T} & 1.16 & 0.07 & 0.07 & 0.07 & 0.08 & 0.09 & 0.09 & 0.10 & 0.12 & 0.13 & 0.15 & 0.17 & 0.21 & 0.23 & 0.25 & 0.29 & 0.34 & 0.40 & 0.49 & 0.64 & 0.92 & 1.64 & 7.45\end{array}$ $\begin{array}{lllllllllllllllllllllllllll}\boldsymbol{C} & 1.18 & 0.07 & 0.08 & 0.08 & 0.09 & 0.10 & 0.11 & 0.12 & 0.13 & 0.15 & 0.17 & 0.19 & 0.23 & 0.25 & 0.29 & 0.32 & 0.38 & 0.45 & 0.55 & 0.72 & 1.02 & 1.80 & 7.45\end{array}$ $\begin{array}{llllllllllllllllllllllllllll}\text { II } & 1.2 & 0.08 & 0.09 & 0.09 & 0.10 & 0.11 & 0.12 & 0.13 & 0.14 & 0.16 & 0.18 & 0.21 & 0.25 & 0.28 & 0.32 & 0.36 & 0.41 & 0.49 & 0.61 & 0.79 & 1.12 & 1.95 & 7.45\end{array}$ $\begin{array}{lllllllllllllllllllllllllllll}\text { 짐 } & 1.22 & 0.09 & 0.10 & 0.10 & 0.11 & 0.12 & 0.13 & 0.14 & 0.16 & 0.18 & 0.20 & 0.23 & 0.28 & 0.31 & 0.35 & 0.39 & 0.45 & 0.54 & 0.66 & 0.86 & 1.21 & 2.09 & 7.45\end{array}$ $\begin{array}{lllllllllllllllllllllllllllll}\text { 山 } & 1.24 & 0.1 & 0.10 & 0.11 & 0.12 & 0.13 & 0.14 & 0.15 & 0.17 & 0.19 & 0.22 & 0.25 & 0.30 & 0.34 & 0.38 & 0.43 & 0.49 & 0.58 & 0.72 & 0.92 & 1.30 & 2.22 & 7.45\end{array}$



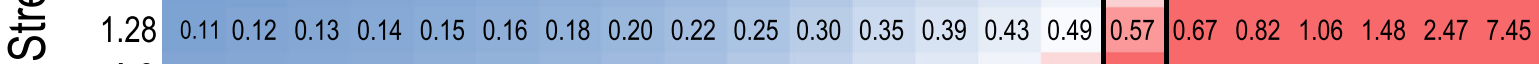

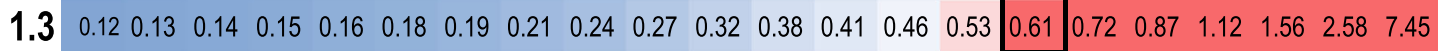
$\begin{array}{llllllllllllllllllllllllllll}1.32 & 0.13 & 0.14 & 0.15 & 0.16 & 0.17 & 0.19 & 0.21 & 0.23 & 0.25 & 0.29 & 0.34 & 0.40 & 0.44 & 0.49 & 0.56 & 0.64 & 0.76 & 0.92 & 1.18 & 1.64 & 2.69 & 7.45\end{array}$ $\begin{array}{lllllllllllllllllllllllllll}1.34 & 0.14 & 0.15 & 0.16 & 0.17 & 0.18 & 0.20 & 0.22 & 0.24 & 0.27 & 0.31 & 0.36 & 0.42 & 0.47 & 0.52 & 0.59 & 0.68 & 0.80 & 0.97 & 1.24 & 1.72 & 2.80 & 7.45\end{array}$ $\begin{array}{llllllllllllllllllllllllllll}1.36 & 0.15 & 0.15 & 0.17 & 0.18 & 0.19 & 0.21 & 0.23 & 0.25 & 0.29 & 0.32 & 0.38 & 0.45 & 0.49 & 0.55 & 0.62 & 0.72 & 0.84 & 1.02 & 1.30 & 1.80 & 2.90 & 7.45\end{array}$ $\begin{array}{lllllllllllllllllllllllllllll}1.38 & 0.15 & 0.16 & 0.17 & 0.19 & 0.20 & 0.22 & 0.24 & 0.27 & 0.30 & 0.34 & 0.40 & 0.47 & 0.52 & 0.58 & 0.65 & 0.75 & 0.88 & 1.07 & 1.36 & 1.87 & 3.00 & 7.45\end{array}$ $\begin{array}{llllllllllllllllllllllllllll}1.4 & 0.16 & 0.17 & 0.18 & 0.20 & 0.21 & 0.23 & 0.25 & 0.28 & 0.32 & 0.36 & 0.41 & 0.49 & 0.54 & 0.61 & 0.68 & 0.79 & 0.92 & 1.12 & 1.42 & 1.95 & 3.09 & 7.45\end{array}$

Fig. 10 Slip tendency Ts with respect to $r=S_{H} / S_{V}$ and $\lambda=P_{p} / S_{V}$ for the fault geometry fixed at a dip angle of $\delta=10^{\circ}$ and $a=40^{\circ}$, where $a$ is the angle between $S_{H}$ and the slip. The friction coefficient $\mu$ is set to be 0.6. The colder and warmer colors correspond to lower and higher values of TS, respectively. Red indicates $\mu \geq 0.6$ (at which slip will occur)



Fig. 11 Temporal change in stress and pore fluid pressure. $\mu_{\text {bed: }}$ incipient frictional coefficient of bedrock; $\mu_{\text {fault: }}$ incipient frictional coefficient of pre-existing fault with its dip angle $\delta_{2}$ 
the fault with a dip angle of approximately $10^{\circ}$ will coincide with the Ts peak.

According to the critical taper model (e.g., Dahlen 1990), the stress state in accretionary wedges is controlled by tectonic/non-tectonic forces, such as a basal drag due to plate convergence, the gravitational force, and the compressional traction acting on the sidewall. The angle between $\sigma_{1}$ and the slope on the seafloor can be derived theoretically. This angle is very sensitive to the effective friction along the basal décollement, as shown in Fig. 8 of Wang and $\mathrm{Hu}$ (2006). In the present study, the slope of the seafloor above the picked fault is less than $4^{\circ}$, and we assume that the pore fluid pressure ratio $\lambda *$ is 0.85 (Tsuji et al. 2014), the intrinsic friction $\mu$ is 0.6 (Byerlee 1978), and the basal effective friction coefficient $\mu_{\mathrm{b}}$ is 0.09 . Figure 8 of Wang and $\mathrm{Hu}$ (2006) indicates that the corresponding angle of $\sigma_{1}$ with respect to the seafloor is approximately $5^{\circ}$, or approximately horizontal. This may support our assumption that the principal stress is horizontal $\left(\sigma_{1}=S_{H}\right)$.

The shallow dip angle can be attributed to the weakness in the fault zone due to excess pore pressure. As shown in Fig. 8, if we use $\lambda^{*}=0.85(\lambda=0.94)$, then the $T s$ value in the shallow dip region ( $\mathrm{N}$ to NW side) increases from $0.05-0.2$ to $0.2-0.6$.

\section{Fault dip azimuth is rotated from the plate convergence vector}

The fault dip azimuth is $\mathrm{N}$ to NW, which is rotated clockwise from the plate convergence vector (N55W to WNW) or from the slip direction of the M6 earthquake (N70W; Wallace et al. 2016). This implies that the plate geometry is affected by factors other than the current stress state.

The shape of the subducting plate boundary for various scales has been revealed through seismic refraction (e.g., Nakanishi et al. 2008), seismic inversion (Kikuchi et al. 2003; Ichinose et al. 2003), tsunami inversion (Baba et al. 2002), and seismic tomography (Nakajima and Hasegawa 2007; Hirose et al. 2008; Yamamoto et al. 2017). Based on seismic analyses, Kodaira et al. (2006) reported a high-velocity doomed body to the south of Kii Peninsula, formed by breaking through the old accretionary prism sediment. A larger-scale geometry was compiled by F. Hirose (http://www.mri-jma.go.jp/ $\mathrm{Dep} / \mathrm{sv} / 2 \mathrm{ken} /$ fhirose/ja/PHS.html) based on research by Baba et al. (2002), Nakajima and Hasegawa (2007), and Hirose et al. (2008). This geometry indicates that the subducting Philippine Sea Plate bends downward toward the Kii Peninsula. Other factors, such as the change in the plate convergence direction at approximately $3 \mathrm{Ma}$ (Takahashi 2006), the hiatus in subduction at 13 to $6 \mathrm{Ma}$ followed by a resumption in subduction (Tsuji et al. 2015), or the subduction of seamount (Kodaira et al. 2000; Kimura et al. 2014), should also be considered elsewhere.

\section{Implications on the spatial variability of $T s$}

As defined in the "Methods/Experimental" section, we can assess the slip likelihood based on $T s$ and the intrinsic friction coefficient. Without knowledge of the friction coefficient, Ts may have two meanings, as follows.

\section{(A) Constant friction model}

Assuming a constant friction everywhere on the fault plane, $T s$ exhibits a relative seismic likelihood. As indicated previously, $T s$ is highest on the high-angle fault in the SE corner, which is most likely to slip first, whereas other regions remain unslipped.

\section{(B) Simultaneous activation model}

Assuming that slip is activated simultaneously over the fault plane, the variation of $T s$ should be compensated by the friction coefficient so that the slip likelihood value $(S L)$ would be identical everywhere on the fault plane. As such, $T s$ is an indication of a relative strength, and the SE corner with highest $T s$ is likely to be strongest, resisting slip until the lower dip region of the fault reaches the critical state.

Tsuji et al. (2014) suggested a zone of very high pore pressure ratio beneath the plate boundary fault, based on the low P-wave velocity estimated from full-wave seismic inversion analysis (Kamei et al. 2012). In the Japan Trench, Ujiie et al. (2013) demonstrated the low friction of the fault material, either due to low intrinsic friction or to increased pore pressure. These inferences suggest that the low $T s$ on the main fault (excluding large-dip SE corner) corresponds to a reduction in effective friction strength either due to excess pore fluid pressure [larger $\lambda$ value in Eq. (10)] or a low intrinsic friction coefficient. On the other hand, as shown in Fig. 7, the larger-dip SE region, which penetrates the high P-wave layer (Shiraishi et al., this volume), would probably have no (or a lower) excess pore fluid pressure, leading to a higher effective strength. Thus, we prefer model B to model A. However, model B must be tested through deep drilling at Site C0002.

\section{Time-dependent Ts}

Here, we consider how the value of Ts can evolve with time at a scale of less than 100 years. Among the factors affecting $T_{s}\left(S_{v}, S_{H}\right.$, and $\left.P_{p}\right)$, the overburden $\left(S_{v}\right)$ remains approximately constant for this time scale. As such, we should consider an increase in $S_{H}$ due to tectonic loading, and an increase in $P_{p}$ with time (e.g., Sibson 1992). These increases are translated as increases in $r$ and $\lambda$ (or $\lambda$ ) in Eq. (10). The tectonic loading during the 
interseismic period would be a few to $10 \mathrm{MPa}$ for subduction zone megathrusts, as inferred from the coseismic stress drop (e.g., Seno 2009) or a numerical simulation (Kinoshita et al. 2013). Accordingly, the value of $r\left(S_{H} / S_{v}\right)$ will increase from 1.2 (set for the present study) to approximately 1.3 for an $S_{v}$ of approximately $100 \mathrm{MPa}$, in this case. The pore fluid pressure ratio can also increase above hydrostatic if any fluid flows into, or is produced in, the fault zone and remains undrained.

These temporal changes are illustrated in Fig. 11 in terms of Mohr's circle. Here, we assume that the incipient frictional coefficient of bedrock, $\mu_{\text {bed }}$, is significantly larger than the incipient frictional coefficient of the pre-existing fault, $\mu_{\text {fault }}$. The dip angle of the pre-existing fault is $\delta_{2}$. In stage A (post-/inter-seismic), the stress field is below the critical state (both for bedrock and a fault). As $r$ and/or $\lambda^{*}$ increases with time, the diameter of Mohr's circle increases, and/or the circle moves to the left. In stage B, the circle touches the Coulomb failure line for the pre-existing fault, but the angle $\delta_{1}$ does not equal that for the fault $\left(\delta_{2}\right)$. Thus, the fault does not reactivate yet. In stage $\mathrm{C}$, in which the circle intersects the fault failure line with dip angle $\delta_{2}$, the pre-existing fault finally slips. However, the strength of the bedrock is much stronger than that of the fault. As such, the rock surrounding the fault will not break. Even if the strength of the bedrock is not very different from that for the fault, the bedrock will not break if its pore fluid pressure is not anomalous [in which case Mohr's circle remains at position (A)].

Based on this model, we investigate the temporal change in Ts with respect to $r$ and $\lambda^{*}$ in Fig. 10. Here, the geometry is fixed at a dip of $10^{\circ}$, and the angle between $S_{H}$ (= slip direction) and the dip azimuth is fixed at $40^{\circ}$, because the geometry will not change with time. The color image indicates the magnitude of $T s$. We recognize that $T s$ increases with increasing $r$ and increasing $\lambda^{*}$. If $r$ increases from 1.0 to 1.4, then $T s$ will increase from 0.01 to 0.16 for a nearly hydrostatic case $\left(\lambda^{*}=0.25\right.$ or $\left.\lambda=0.7\right)$, whereas $T s$ increases from 0.04 to 0.79 for an overpressure case $(\lambda *=$ 0.85 or $\lambda=0.94$ ).

If we accept $\lambda^{*}=0.85$ on the fault (Tsuji et al. 2014) $(\lambda \sim 0.94)$, the fault near Site C0002 is very close to failure for $r>1.2$ (note that, here, the friction coefficient is assumed to be 0.6). In any case, drilling into the fault zone at Site C0002 will reveal its strength and stress. This will provide ground-truth evidence at this site, which can in turn be extrapolated to the 3D fault zone, and we can take an important step toward a better understanding of the slip likelihood of the Nankai seismogenic zone megathrust.

\section{Conclusions}

From the reprocessed 3D PSDM volume, we obtained a fine-scale geometry (dip angle and azimuth) of the plate boundary megathrust near the updip edge on the landward side of the Nankai seismogenic zone. This has enabled us to assess the degree to which the fault geometry affects the slip tendency.

1. The depth of the fault surface ranges from 3500 to $6500 \mathrm{mbsf}$. The geometry of the fault surface is divided into three groups: low dip $\left(10^{\circ}-15^{\circ}\right)$ trending $\mathrm{NW}$ to $\mathrm{N}$ in the NE region, intermediate dip (approximately $25^{\circ}$ ) trending north in the western region, and high dip $\left(30^{\circ}-40^{\circ}\right)$ trending NW in the SE corner. This higher-angle structure branches out from the low-angle reflector.

2. Shear and normal stresses and the slip tendency are estimated from fault dip and the azimuth for a geomechanical model with $S_{H} / S_{v}=1.2, S_{h}=S_{v}$, and $P_{p} / S_{v}=0.7$ (the near-hydrostatic condition in which the normalized pore pressure ratio, $\lambda^{*}$, is 0.25 ). The slip tendency is sensitive to the variation of fault geometry and is low in the low-angle dip region and high in the high-angle dip region. A low slip tendency region would correspond to a weaker region due to excess pore pressure or a low intrinsic friction coefficient, assuming that the entire fault is in a Coulomb-failure condition simultaneously.

3. Using the high $\lambda^{*}(\sim 0.85)$ at the fault zone, the fault beneath IODP Site C0002 is very close to failure, assuming an intrinsic frictional coefficient of 0.6.

\section{Appendix}

\section{Calculation of normal/shear stress and slip tendency}

First, we define the $y$-axis as being parallel to $\sigma_{1}=\sigma_{H}$, the $x$-axis as being parallel to $\sigma_{h}$, and the $z$-axis as being parallel to $\sigma_{v}$. Considering the effective principal stresses, the stress tensor $\Sigma$ is expressed as

$$
\Sigma=\left[\begin{array}{ccc}
\sigma_{h} & 0 & 0 \\
0 & \sigma_{H} & 0 \\
0 & 0 & \sigma_{v}
\end{array}\right]=\left[\begin{array}{ccc}
S h-P p & 0 & 0 \\
0 & S H-P p & 0 \\
0 & 0 & S_{v}-P p
\end{array}\right]
$$

We set $S_{H}$ oriented to N55W, so that the angle ( $\alpha$ ) between $S_{H}$ (= slip) and the dip azimuth $(\psi)$ at each point on the fault surface is defined as $\alpha=\psi-(-55)$. Based on these definitions, the normal vector at each point on the fault is obtained as

$$
\mathbf{n}=\left[\begin{array}{c}
\sin \alpha \sin \delta \\
\cos \alpha \sin \delta \\
\cos \delta
\end{array}\right]
$$


The stress vector (p) acting at a point on the fault surface by the stress tensor $\Sigma$ is derived from Cauchy's formula:

$$
\mathbf{p}=\sum \cdot \mathbf{n}
$$

Thus, the normal stress $\left(\sigma_{n}\right)$ acting at any point on the fault surface can be derived by taking the inner product of $\mathbf{p}$ and $\mathbf{n}$.

For the shear stress, we need to define the direction of slip, which we assume to be parallel to the $S_{H}$ direction (N55 W), i.e., the unit vector parallel to the shear stress $(\tau)$ is

$$
\boldsymbol{t}=\left[\begin{array}{c}
0 \\
-A \cos \delta \cos ^{-1} \alpha \\
A \sin \delta
\end{array}\right]
$$

where $A=\left(\frac{\cos ^{2} \delta}{\cos ^{2} \alpha}+\sin ^{2} \delta\right)^{-1 / 2}$.

From (A1) and (A2), the effective normal stress is expressed as

$\boldsymbol{\sigma}_{\boldsymbol{n}_{-} \boldsymbol{e}}=\boldsymbol{n}^{T} \cdot(\boldsymbol{\Sigma} \cdot \boldsymbol{n})=(\sin \alpha \sin \delta)^{2} \sigma_{h}+(\cos \alpha \sin \delta)^{2} \sigma_{H}+(\cos \delta)^{2} \sigma_{v}$.

Since we assume a triaxial condition $\left(\sigma_{h}=\sigma_{v}\right)$, we have

$\boldsymbol{\sigma}_{\boldsymbol{n} \_} \boldsymbol{e}=\left((\sin \alpha \sin \delta)^{2}+(\cos \delta)^{2}\right) \sigma_{\nu}+(\cos \alpha \sin \delta)^{2} \sigma_{H}$

The shear stress $\tau$ is

$$
\mathbf{\tau}=\boldsymbol{t}^{T} \cdot(\boldsymbol{\Sigma} \cdot \boldsymbol{n})=A \sin \delta \cos \delta\left(\sigma_{H}-\sigma_{v}\right)
$$

The shear stress is oriented in part seaward due to the seaward dipping region. This is likely due to artificial noise that could not be removed from the migration noise reduction process. In any case, we exclude such cases and set $\tau=$ 0 if $\tau<0$

Slip tendency $T s$ is calculated by dividing (A4) by (A5):

$T_{s}=\frac{\sin \delta \cos \delta\left(\sigma_{H}-\sigma_{\nu}\right)}{\sqrt{\left(\frac{\cos \delta}{\cos \alpha}\right)^{2}+\sin ^{2} \delta}\left[\left(\cos ^{2} \delta+\sin ^{2} \alpha \sin ^{2} \delta\right) \sigma_{v}+(\cos \alpha \sin \delta)^{2} \sigma_{\nu}\right]}$.

Here, we rewrite (A4) through (A6) by introducing $r$ $\left(=S_{H} / S_{v}\right)$ and $\lambda\left(=P_{p} / S_{v}\right)$ :

$\sigma_{n_{-} e}=\left[\left((\sin \alpha \sin \delta)^{2}+(\cos \delta)^{2}\right)(1-\lambda)+(\cos \alpha \sin \delta)^{2}\right.$
$(r-\lambda)] S_{\nu}$

$$
\tau=A \sin \delta \cos \delta(r-1) S_{v}
$$

$$
T_{s}=\frac{\sin \delta \cos \delta(r-1)}{\sqrt{\left(\frac{\cos \delta}{\cos \alpha}\right)^{2}+\sin ^{2} \delta}\left[\left(\cos ^{2} \delta+\sin ^{2} \alpha \sin ^{2} \delta\right)(1-\lambda)+(\cos \alpha \sin \delta)^{2}(r-\lambda)\right]} .
$$

\section{Additional file}

Additional file 1: Dataset supporting the conclusion. (ZIP $1803 \mathrm{~kb}$ )

\section{Abbreviations}

IODP: International Ocean Discovery Program; mbsf: Meters below sea floor; NanTroSEIZE: Nankai Trough Seismogenic Zone Experiments; Ts: Slip tendency

\section{Acknowledgements}

The authors would like to thank Gaku Kimura, Yasuhiro Yamada, Eiichiro Araki, and Kyuichi Kanagawa for their fruitful discussion. MK gratefully acknowledges Kotaro Fujita for his assistance in finalizing the figures.

\section{Funding}

The present study was supported by JSPS KAKENHI Grant Number JP15H05717, and by the Ministry of Education, Culture, Sports, Science and Technology (MEXT) through management expenses grants at the Research and Development Center for Ocean Drilling Science (ODS) and the Center for Deep Earth Exploration (CDEX) of Japan Agency for Marine-Earth Science and Technology (JAMSTEC)

Availability of data and materials

The dataset supporting the conclusions of the present study is included in the manuscript and associated Additional file 1. For those who are interested in the original 3D seismic volume, please contact Masataka Kinoshita (masa@eri.u-tokoyo.ac.jp).

\section{Authors' contributions}

MK proposed the method and directed the overall project. KS processed the 3D seismic volume data and contributed to seismic interpretation. ED actually picked the fault surface under the supervision of MK. YH contributed to the geological/geotechnical interpretation of Ts contrast. WL helped in setting the regional principal stresses. All of the authors read and approved the final manuscript.

\section{Authors' information}

MK has been committed to the IODP NanTroSEIZE project, which was started in 2007, as a key member of the project coordination team.

\section{Competing interests}

The authors declare that they have no competing interests.

\section{Publisher's Note}

Springer Nature remains neutral with regard to jurisdictional claims in published maps and institutional affiliations.

\section{Author details}

${ }^{1}$ Earthquake Research Institute, The University of Tokyo, 1-1-1 Yayoi, Bunkyo-ku, Tokyo 113-0032, Japan. ${ }^{2}$ Research and Development Center for Ocean Drilling Science (ODS), Japan Agency for Marine-Earth Science and Technology (JAMSTEC), 3173-25 Showa-machi, Kanazawa-ku, Yokohama, Kanagawa 236-0001, Japan. ${ }^{3}$ Kingston University, Kingston Upon Thames, UK. ${ }^{4}$ Faculty of Science and Technology, Kochi University, Kochi 780-8072, Japan.

${ }^{5}$ Graduate School of Engineering, Kyoto University, Kyoto 606-8501, Japan. 
Received: 26 March 2018 Accepted: 20 December 2018 Published online: 23 January 2019

\section{References}

Araki E, Saffer DM, Kopf AJ, Wallace LM, Toshinori Kimura T, Yuya Machida Y, Satoshi Ide S, Davis EE, IODP Expedition 365 shipboard scientists (2017) Recurring and triggered slow-slip events near the trench at the Nankai Trough subduction megathrust. Science 356: 1157-1160. doi:https://doi.org/ 10.1126/science.aan3120.

Baba T, Cummins PR, Hori T, Kaneda Y (2006) High precision slip distribution of the 1944 Tonankai earthquake inferred from tsunami waveforms: possible slip on a splay fault. Tectonophysics 426:119-134. https://doi.org/10.1016/j. tecto.2006.02.015.

Baba T, Tanioka Y, Cummins PR, Uhira K (2002) The slip distribution of the 1946 Nankai earthquake estimated from tsunami inversion using a new plate model. Phys Earth Planet Inter 132:59-73.

Brown ET, Hoek E (1978) Trends in relationship between measured in situ stresses and depth. Int J Rock Mech Min Sci Geomech Abst 15:211-215.

Byerlee J (1978) Friction of rocks. Pure Appl Geophys 116:615-626.

Dahlen FA (1990) Critical taper model of fold-and-thrust belts and accretionary wedges. Annual Rev Earth Planet Sci 18:55-99.

DeMets C, Gordon RG, Argus DF (2010) Geologically current plate motions. Geophysical J Int 181:1-80. https://doi.org/10.1111/j.1365-246X.2009.04491.X.

Erickson SN, Jarrard RD (1998) Velocity-porosity relationships for water-saturated siliciclastic sediments. J Geophys Res 103(B12):30,385-30,406. https://doi.org/ 10.1029/98JB02128.

Expedition 326 Scientists (2011) NanTroSEIZE stage 3: plate boundary deep riser: top hole engineering. IODP Preliminary Report 326. doi:https://doi.org/10. 2204/iodp.pr.326.2011.

Hasegawa A, Yoshida K, Okada T (2011) Nearly complete stress drop in the 2011 Mw 9.0 off the Pacific coast of Tohoku earthquake. Earth Planets Space 63: 703-707. https://doi.org/10.5047/eps.2011.06.007.

Henry P, Kanamatsu T, Moe KT (2012) the Expedition 333 Scientists Proc IODP (Vol. 333) Tokyo. Integrated Ocean Drilling Program Management International Inc. https://doi.org/10.2204/iodp.proc.333.2012.

Hirose F, Nakajima J, Hasegawa A (2008) Three-dimensional seismic velocity structure and configuration of the Philippine Sea slab in southwestern Japan estimated by double-difference tomography. J Geophys Res 113:B09315. https://doi.org/10.1029/2007JB005274.

Ichinose GA, Thio HK, Somerville PG, Sato T, Ishii T (2003) Rupture process of the 1944 Tonankai earthquake (Ms 8.1) from the inversion of teleseismic and regional seismograms. J Geophys Res 108 (B10):2497. doi:https://doi.org/10. 1029/2003JB002393, 2003.

Ito Y, Asano Y, Obara K (2009) Very low-frequency earthquakes indicate a transpressional stress regime in the Nankai accretionary prism. Geophys Res Lett 36:L20309. https://doi.org/10.1029/2009GL039332.

Kamei R, Pratt RG, Tsuji T (2012) Waveform tomography imaging of a mega-splay fault system in the seismogenic Nankai subduction zone. Earth Planet Sci Lett 317-318:343-353.

Kikuchi M, Nakamura M, Yoshikawa K (2003) Source rupture processes of the 1944 Tonankai earthquake and the 1945 Mikawa earthquake derived from low-gain seismograms. Earth Planets and Space 55:159-172.

Kimura G, Hashimoto Y, Kitamura Y, Yamaguchi A, Koge H (2014) Middle Miocene swift migration of the TाT triple junction and rapid crustal growth in Southwest Japan: a review. Tectonics 33:1219-1238. https://doi.org/10. 1002/2014TC003531.

Kimura G, Moore GF, Strasser M, Screaton E, Curewitz D, Streiff C, Tobin H (2011) Spatial and temporal evolution of the megasplay fault in the Nankai Trough. Geochem Geophys Geosyst 12:Q0A008. https://doi.org/10. 1029/2010GC003335.

Kinoshita M, Kimura G, Saito S (2014) Chapter 4.4.2 Seismogenic processes revealed through the Nankai Trough seismogenic zone experiments: Core, log, geophysics and observatory measurements. In: Stein R, Blackman DK, Inagaki F, Larsen H-C (eds) Developments in Marine Geology Vol 7: Earth and Life Processes Discovered from Subseafloor Environment. Elsevier, pp 641-670. https://doi.org/10.1016/B978-0-444-62617-2.00021-9.

Kinoshita M, Tobin H, Ashi J, Kimura G, Lallement S, Screaton EJ, Curewitz D, Masago H, Moe KT (2009) The Expedition 314/315/316 Scientists Proc. IODP, 314/315/316. (Integrated Ocean Drilling Program Management International, Inc.), Washington, DC. https://doi.org/10.2204/iodp.proc. 314315316.2009 .
Kinoshita, M., Tobin, H.J. (2013) Interseismic stress accumulation at the locked zone of Nankai Trough seismogenic fault off Kii Peninsula, Tectonophysics, 600C, 153-164. https://doi.org/10.1016/j.tecto.2013.03.015

Kitajima H, Saffer D, Sone H, Tobin H, Hirose T (2017) In situ stress and pore pressure in the deep interior of the Nankai accretionary prism, integrated ocean drilling program site C0002. Geophy Res Lett 44:9644-9652. https:// doi.org/10.1002/2017GL075127.

Kodaira S, Hori T, Ito A, Miura S, Fujie G, Park JO, Baba T, Sakaguchi H, Kaneda Y (2006) A cause of rupture segmentation and synchronization in the Nankai trough revealed by seismic imaging and numerical simulation. J Geophys Res 111:B09301. https://doi.org/10.1029/2005JB004030.

Kodaira S, Takahashi N, Nakanishi A, Miura S, Kaneda Y (2000) Subducted seamount imaged in the rupture zone of the 1946 Nankaido earthquake. Science 289:104-106.

Kopf A, Araki E, Toczko S, (2011) Expedition 332 Scientists NanTroSElZE Stage 2: riserless observatory. International Ocean Discovery Program Prel Rept 332. doi:https://doi.org/10.2204/iodp.pr.332.2011.

Kopf A, Saffer D, Toczko S, (2016) Expedition 365 Scientists Expedition 365 Preliminary Report: NanTroSEIZE Stage 3: Shallow Megasplay Long-Term Borehole Monitoring System (LTBMS). International Ocean Discovery Program Prel Rept 332 doi:https://doi.org/10.14379/iodp.pr.365.2016.

Miyakawa A, Otsubo M (2015) Applicability of slip tendency for understanding long-term fault activity: a case study of active faults in northeastern Japan. J JSCE 3:105-114. https://doi.org/10.2208/journalofjsce.3.1_105.

Miyazaki S, Heki K (2001) Crustal velocity field of Southwest Japan: subduction and arc-arc collision. J Geophys Res 106:4305-4326. https:// doi.org/10.1029/2000JB900312.

Moore GF, Bangs NL, Taira A, Kuramoto S, Pangborn E, Tobin HJ (2007) Threedimensional splay fault geometry and implications for tsunami generation. Science 318:1128-1131. https://doi.org/10.1126/science.1147195.

Morris A, Ferrill DA, Henderson DB (1996) Slip-tendency analysis and fault reactivation. Geology 24:275-278. https://doi.org/10.1130/00917613(1996)024<0275:STAAFR>2.3.CO;2.

Nakajima J, Hasegawa A (2007) Subduction of the Philippine Sea plate beneath southwestern Japan: slab geometry and its relationship to arc magmatism. J Geophys Res 112:B08306. https://doi.org/10.1029/2006JB004770.

Nakanishi A, Kodaira S, Miura S, Ito A, Sato T, Park JO, Kido Y, Kaneda Y (2008) Detailed structural image around splay-fault branching in the Nankai subduction seismogenic zone: results from a high-density ocean bottom seismic survey. J Geophys Res 113:B03105. https://doi.org/10.1029/2007JB004974.

Nakano M, Hyodo M, Nakanishi A, Yamashita M, Hori T, Kamiya S, Suzuki K, Tonegawa T, Kodaira S, Takahashi N, Kaneda Y (2018) The 2016 off Southeast Mie prefecture earthquake $(\mathrm{mw}=5.9)$ as an indicator of preparatory processes of the next Nankai trough megathrust earthquake. Progress in earth and planetary science. Accepted in July 2018.

Obana K, Kodaira S (2009) Low-frequency tremors associated with reverse faults in a shallow accretionary prism. Earth Planet Sci Lett 287:168-174. https://doi. org/10.1016/j.epsl.2009.08.005.

Obara K, Ito Y (2005) Very low frequency earthquakes excited by the 2004 off the Kii peninsula earthquakes: a dynamic deformation process in the large accretionary prism. Earth Planets Space 57:321-326. https://doi.org/10.1186/ BF03352570.

Obara K, Kato A (2016) Connecting slow earthquakes to huge earthquakes. Science 353:253-257. https://doi.org/10.1126/science.aaf1512.

Park JO, Fujie G, Wijerathne L, Hori T, Kodaira S, Fukao F, Moore GF, Bangs NL, Kuramoto S, Taira A (2010) A low velocity zone with weak reflectivity along the Nankai subduction zone. Geology 38:283-286. https://doi.org/10.1130/G30205.1.

Rummel F, Möhring-Erdmann G, Bäumgartner J (1986) Stress constraints and Hydrofracturing stress data for the continental crust. PAGEOPH 124:875-894.

Saffer D, McNeill L, Byrne T, Araki E, Toczko S, Eguchi N et al (2010) Proc IODP (Vol. 319) Tokyo: Integrated Ocean Drilling Program management international Inc. https://doi.org/10.2204/iodp.proc.319.104.2010.

Saito S, Underwood MB, Kubo Y (2010) The expedition 322 scientists proc IODP (Vol. 322) Tokyo. Integrated Ocean drilling program management international, Inc. https://doi.org/10.2204/iodp.proc.322.2010.

Screaton EJ, Kimura G, Curewitz D, (2009) et al. The expedition 316 scientists expedition 316 summary. In M. Kinoshita, H. Tobin, J. Ashi, G. Kimura, S. Lallemant, E. J. Screaton. (Eds.), Proc. IODP (Vol. 314/315/316). Washington, DC: Integrated Ocean Drilling Program Management International Inc doi: https://doi.org/10.2204/iodp.proc.314315316.131.2009. 
Seno T (2009) Determination of the pore fluid pressure ratio at seismogenic megathrusts in subduction zones: implications for strength of asperities and Andean-type mountain building. J Geophys Res 114:B05405. https://doi.org/ 10.1029/2008JB005889.

Shiraishi K, Moore GF, Yamada Y, Kinoshita M, Sanada Y, Kimura G (2016) Improved 3D seismic images of dynamic deformation in the Nankai trough off Kumano, abstract T42C-06 presented at 2016 fall meeting, AGU, San Francisco, 12-16, Dec. Seismogenic zone structures revealed by improved 3D seismic image in the Nankai Trough off Kumano. in review SPEPS.

Sibson RH (1992) Implications of fault-valve behavior for rupture nucleation and recurrence. Tectonophysics 211:283-293. https://doi.org/10.1016/ 0040-1951(92)90065-E.

Strasser M, Dugan B, Kanagawa K, Moore GF, Toczko S, Maeda L et al (2014) Proc IODP (Vol. 338) Yokohama: Integrated Ocean Drilling Program 12: Q0AD17. https://doi.org/10.2204/iodp.proc.338.2014.

Sugioka H, Okamoto T, Nakamura T, Ishihara Y, Ito A, Obana K, Kinoshita M, Nakahigashi K, Shinohara M, Fukao Y (2012) Tsunamigenic potential of the shallow subduction plate boundary inferred from slow seismic slip. Nat Geosci 5:414-418. https://doi.org/10.1038/NGEO1466.

Takahashi M (2006) Tectonic development of Japanese Islands controlled by Philippine Sea plate motion (in Japanese with English abstract). J Geogr 115:116-123.

Templeton EL, Rice JR (2008) Off-fault plasticity and earthquake rupture dynamics: 1. Dry materials or neglect of fluid pressure changes. J Geophys Res 113:B09306. https://doi.org/10.1029/2007JB005529.

Tobin H, Henry P, Vannucchi P, Screaton E (2014) Chapter 4.4.1 Subduction zones: structure and deformation history. In: Stein R, Blackman DK, Inagaki F, Larsen $\mathrm{H}-\mathrm{C}$ (eds) Developments in marine geology Vol 7: earth and life processes discovered from subseafloor environment. Elsevier, pp 599-640. https://doi.org/10.1016/B978-0-444-62617-2.00020-7.

Tobin H, Hirose T, Saffer D, Toczko S, Maeda L, Kubo Y, Boston B, Broderick A, Brown K, Crespo-Blanc A, Even E, Fuchida S, Fukuchi R, Hammerschmidt S, Henry P, Josh M, Jurado MJ, Kitajima H, Kitamura M, Maia A, Otsubo M, Sample J, Schleicher A, Sone H, Song C, Valdez R, Yamamoto Y, Yang K, Sanada Y, Kido Y, Hamada Y (2015) Site C0002. In: Tobin H, Hirose T, Saffer D, Toczko S, Maeda L, Kubo Y (eds) Expedition 348 scientists, proc IODP 348. TX (Integrated Ocean Drilling Program), College Station. https://doi.org/10.2204/ iodp.proc.348.103.2015.

Tobin, H., Kinoshita, M., Ashi, J., Lallemant, S., Kimura, G., Screaton, E., (2009) et al. n.d.. NanTroSEIZE stage 1 expeditions 314, 315, and 316: first drilling program of the Nankai trough seismogenic zone experiment. Sci Drill 8: 4-17. https:// doi.org/10.2204/iodp.sd.8.01.2009.

Tobin HJ, Kinoshita M (2006) NanTroSEIZE: the IODP Nankai trough seismogenic zone experiment. Sci Drill 2:23-27. https://doi.org/10.2204/iodp.sd.2.06.2006.

Tong H, Yin A (2011) Reactivation tendency analysis: a theory for predicting the temporal evolution of preexisting weakness under uniform stress state. Tectonophysics 503:195-200. https://doi.org/10.1016/j.tecto.2011.02.012

Tsuji T, Ashi J, Strasser M, Kimura G (2015) Identification of the static backstop and its influence on the evolution of the accretionary prism in the Nankai trough. Earth Planet Sci Lett 431:15-25. https://doi.org/10.1016/j. epsl.2015.09.011.

Tsuji T, Kamei R, Pratt RG (2014) Pore pressure distribution of a mega-splay fault system in the Nankai trough subduction zone: insight into up-dip extent of the seismogenic zone. Earth Planet Sci Lett 396:165-178. https://doi.org/10. 1016/j.epsl.2014.04.011.

Ujiie K, Tanaka H, Saito T, Tsutsumi A, Mori JJ, Kameda J, Brodsky EE, Chester FM, Eguchi N, Toczko S, Expedition 343 and 343T Scientists (2013) Low Coseismic shear stress on the Tohoku-Oki megathrust determined from laboratory experiments. Science 342:1211-1214. https://doi.org/10.1126/science. 1243485 .

Wallace LM, Araki E, Saffer D, Wang X, Roesner XA, Kopf A, Nakanishi A, Power W, Kobayashi R, Kinoshita C, Toczko S, Kimura T, Machida Y, Carr S (2016) Near-field observations of an offshore Mw 6.0 earthquake from an integrated seafloor and subseafloor monitoring network at the Nankai Trough, Southwest Japan. J Geophys Res Solid Earth 121:8338-8351. https://doi.org/10.1002/2016JB013417.

Wang K, Hu Y (2006) Accretionary prisms in subduction earthquake cycles: the theory of dynamic coulomb wedge. J Geophys Res 111:B06410. https://doi. org/10.1029/2005JB004094.

Yamamoto Y, Takahashi T, Kaiho Y, Obana K, Nakanishi A, Kodaira K, Kaneda Y (2017) Seismic structure off the Kii peninsula, Japan, deduced from passive- and active-source seismographic data. Earth Planet Sci Lett 461:163-175. https://doi.org/10.1016/j.epsl.2017.01.003.

Yokota Y, Ishikawa T, Watanabe S, Tashiro T, Asada A (2016) Seafloor geodetic constraints on interplate coupling of the Nankai trough megathrust zone. Nature 534:374-377. https://doi.org/10.1038/nature17632.

Zoback M (2007) Reservoir Geomechanics. Cambridge University Press. https:// doi.org/10.1017/CBO9780511586477.

\section{Submit your manuscript to a SpringerOpen ${ }^{\circ}$ journal and benefit from:}

- Convenient online submission

- Rigorous peer review

- Open access: articles freely available online

- High visibility within the field

- Retaining the copyright to your article

Submit your next manuscript at $\boldsymbol{\nabla}$ springeropen.com 